\title{
Parathormone and Perinatal Calcium Homeostasis
}

\author{
HEINRICH K. SCHEDEWIE, WILLIAM D. ODELL, DELBERT A. FISHER, SIEGFRIED R. KRUTZIK, \\ MICHAEL DODGE, LARRY COUSINS, AND WILLIAM P. FISER
}

\begin{abstract}
Department of Pediatrics, University of Arkansas College of Medicine, Little Rock, Arkansas, and Departments of Pediatrics, Medicine, and Obstetrics and Gynecology, UCLA-Harbor General Hospital, Torrance, California, USA
\end{abstract}

\section{Summary}

Plasma parathormone (PTH) and calcium concentrations were measured in 309 specimens collected from 190 newborns during the first 7 days of life. The patient material consisted of 51 preterm, 130 term, and 9 postterm infants, including 22 infants of diabetic mothers (IDM), 38 infants with hypocalcemia, and 25 asphyxiated infants. PTH was detectable, although in low concentrations, in cord blood samples despite the presence of elevated calcium concentrations. Postpartum, PTH concentrations in term, appropriate for gestational age (AGA) infants remained low during the first 2 days of life; a significant $(P<0.05)$ and sustained increase in plasma hormone levels was noted starting on day 3. PTH concentrations in IDM and preterm infants remained low for 3 days and a significant hormone increase did not occur until day 4.

Hypocalcemia was common in IDM and asphyxiated infants; these infants accounted for two-thirds of all hypocalcemic infants. The profile of plasma calcium in IDM during the first week of life was different than that of any other group of infants. Plasma calcium concentrations remained depressed over this period of time and exhibited a temporary drop on day 4 accompanied by an increase in plasma PTH levels. Asphyxiated infants exhibited low plasma calcium concentrations, despite PTH levels that were significantly $(P<\mathbf{0 . 0 0 7})$ higher than those of age-matched term AGA newborns.

\section{Speculation}

Basal PTH secretion is present at birth, several days before the parathyroid glands appear to become responsive to hypocalcemia. Furthermore, in cord blood PTH is detectable in spite of elevated calcium concentrations. The present observations suggest that nonsuppressible PTH secretion, previously described in short-term animal experiments, also occurs in the human fetus exposed to long-standing intrauterine hypercalcemia, with the implication that PTH secretion in man may be regulated by control mechanisms in addition to calcium feedback. There is anatomical and pharmacologic evidence to implicate the autonomic nervous system in this control.

Hypocalcemia is a frequent problem in early postnatal life (11, $20,37,47)$. Between 1970 and 1971,44 of 1390 newborns $(3.2 \%)$ delivered at Harbor General Hospital, UCLA, presented with socalled "first day hypocalcemia" defined as serum calcium levels of $\leq 7 \mathrm{mg} / \mathrm{dl}$ during the first $36-48 \mathrm{hr}$ of life (32). Two-thirds of these infants were premature (gestation less than 38 weeks). The etiology of first day hypocalcemia remains unclear. A number of authors $(17,19,46)$ have assumed an immaturity of parathyroid gland function, but because of methodologic limitations parathormone (PTH) measurements have been performed in only a few instances. Moreover, when PTH concentrations have been determined, results from different laboratories have sometimes been contradictory. Lequin et al. (25), Tsang et al. (48) and Whatney and Rudd (49) have observed mean PTH concentrations in cord blood equal to or higher than maternal hormone concentrations, whereas David and Anast (13) reported undetectable cord PTH levels in over $80 \%$ of their newborns. Tsang et al. (48) measured PTH in 9 of 19 mothers $(94 \pm 11$; mean \pm SE) and 14 of 19 cord blood samples $(117 \pm 17)$, but were unable to detect any correlation between serum-ionized calcium on the one hand and PTH levels on the other in either maternal, cord, or infant blood between birth and age 7 days. David and Anast (13) reported similar results, yet they did observe an increase in plasma PTH in 23 of 36 infants beyond age $48 \mathrm{hr}$, and this increase correlated with a gradual rise of the low neonatal calcium concentrations toward normal. Finally, there are conflicting data regarding PTH responsiveness to acute hypocalcemia in the newborn. During exchange transfusion with citrated blood, Tsang et al. (48) found increasing PTH levels, but no detectable correlation with total or ionized plasma calcium. David and Anast (12) noted little or no PTH change in 9 of 13 infants undergoing exchange transfusion; only 4 infants older than $48 \mathrm{hr}$ showed a clear-cut increase in plasma PTH in response to falling plasma calcium concentrations.

Some of these inconsistencies may be explained by the fact that different PTH antisera were employed in the above studies and different PTH peptides may have been measured. The circulating PTH peptide complex consists of a mixture of at least three different hormone species with molecular weights approximating 9500,7500 , and 4500 (43). These hormone species show differences in biologic as well as immunologic activity. The GP-1 antibody used in this study is directed against both the amino and carboxyl terminal fragments of the PTH molecule. It thus recognizes intact PTH as well as biologically inactive cleavage products. This study details data gathered on newborns of different gestational ages and health states, in whom single or sequential blood samples were collected for the measurement of plasma PTH and calcium.

\section{MATERIALS}

Between October 1974 and October 1975, 309 blood samples were collected from 190 infants who were 1-7 days of age. The patient population consisted predominantly of infants from Spanish-American ethnic background who were delivered on the Perinatal Service at UCLA-Harbor General Hospital. Written informed consent (52) was obtained from each mother before drawing blood. Table 1 shows the distribution of patients according to gestational age, sex, and type of delivery, as well as the incidence of perinatal disorders. There were equal numbers of male and female newborns in the three gestational age groups. About $40 \%$ of the premature and $30 \%$ of the term infants were delivered by cesarean section, the majority of which were performed under spinal anesthesia. Sequential blood samples were obtained in 52 of the 190 patients. The following figures list the number of patients and, in parentheses, the respective number of sequential samples collected from each individual: 24 (2), 7 (3), 6 (4), 10 (5), 4 (6), and 1 (7). Table 2 shows the distribution of blood samples according to gestational age, postnatal age, type of delivery, and 
Table 1. Distribution of infants according to gestational age groups, sex, type of delivery, and perinatal disorders

\begin{tabular}{lccccccc}
\hline Gestational age groups & Total infants & $\begin{array}{c}\text { Female in- } \\
\text { fants }\end{array}$ & Male infants & $\begin{array}{c}\text { Vaginal deliv- Cesarean sec- } \\
\text { eries }\end{array}$ & $\begin{array}{c}\text { IDM } \\
\text { tion deliveries }\end{array}$ & $\begin{array}{c}\text { Hypocalcemic } \\
\text { infants }\end{array}$ & $\begin{array}{c}\text { Asphyxiated } \\
\text { infants }\end{array}$ \\
\hline $\begin{array}{l}\text { Preterm } \\
\text { infants }\end{array}$ & 51 & 24 & 27 & 32 & 19 & 10 & 21 \\
$\begin{array}{l}\text { Term } \\
\text { infants }\end{array}$ & 130 & 66 & 64 & 92 & 38 & 12 & 15 \\
$\quad \begin{array}{l}\text { Postterm } \\
\text { infants }\end{array}$ & 9 & 4 & 5 & 6 & 3 & 0 & 2 \\
Total & 190 & 94 & 96 & 130 & 60 & 22 & 38 \\
\hline
\end{tabular}

Table 2. Distribution of blood samples according to gestational age, postnatal age, type of delivery, and perinatal disorders

\begin{tabular}{ccccccccc}
\hline Postnatal age groups & No. of samples & $\begin{array}{c}\text { Vaginal deliv- } \\
\text { eries }\end{array}$ & $\begin{array}{c}\text { Cesarean sec- } \\
\text { tion deliveries }\end{array}$ & $\begin{array}{c}\text { Term AGA in- } \\
\text { fants }\end{array}$ & $\begin{array}{c}\text { Preterm in- } \\
\text { fants }\end{array}$ & \multicolumn{2}{c}{$\begin{array}{c}\text { Hypocal- } \\
\text { DM }\end{array}$} & $\begin{array}{c}\text { Asphyxiated } \\
\text { cemic infants }\end{array}$ \\
\hline infants
\end{tabular}

perinatal history. Not listed in the Table 2 are small for gestational age term newborns ( 7 samples), large for gestational age term infants (55), and postterm infants (10).

Gestational age was determined from the mother's menstrual history and from postnatal examination of the newborn, utilizing the scoring system and regression line of Dubowitz et al. (16). Where menstrual history and objective clinical assessment differed, the gestational age as determined by physical examination was used. All physical examinations were performed by the same person. Term infants were defined by a gestational age $\geq 38$ but $\leq 42$ weeks. Preterm infants ranged in age from 26 to 37 weeks, 12 were $\leq 32$ weeks of gestation. The classification of newborns by birth weight as small, appropriate (AGA), and large for gestational age was determined according to the Denver Intrauterine Growth Curves (5). Eleven infants had a birth weight of $\leq 1500 \mathrm{~g}$; the lowest was $710 \mathrm{~g}$. Five babies weighed over $4500 \mathrm{~g}$.

The IDM consisted of newborns with a maternal history of either diabetes mellitus prior to pregnancy or glucose intolerance during gestation as defined by O'Sullivan and Mahan (33). According to White's criteria (50), only 1 mother had class D diabetes, 3 mothers had class $C$ disease, 2 had class B, and 17 class A diabetes. APGAR scores were recorded at 1 and $5 \mathrm{~min}$ in all infants. Asphyxia was defined as a 5-min score of less than seven points. Thirty-eight patients presented with neonatal hypocalcemia (Table 3), which was defined for this study as a plasma calcium concentration of $\leq 7.5 \mathrm{mg} / \mathrm{dl}$.

\section{METHODS}

Free flowing blood specimens were obtained by puncture of a cubital vein or of the warmed heel (34). The samples were collected in EDTA tubes over ice, centrifuged immediately at $4^{\circ}$, and kept frozen at $-20^{\circ}$. Plasma calcium determinations were carried out in duplicate using an atomic absorption spectrophotometer (Perkin-Elmer model 305B). Plasma PTH levels were determined by a double antibody radioimmunoassay, a modification of the technique described by Berson et al. (7). All samples were measured in the same assay. PTH antibody GP-1, kindly supplied by Dr. J. Potts, Jr., was used in a final dilution of $7.5 \times 10^{-5}$. The immunologic properties of this PTH antibody have been well characterized and include specific binding sites within the amino acid sequence $15-24$ in the amino terminal portion of the PTH molecule, as well as the amino acid sequence 53-84 in the carboxyl terminus $(42,43)$. PTH concentrations were expressed as microliter equivalents ( $\mu \mathrm{l} \mathrm{Eq)} \mathrm{relative} \mathrm{to} \mathrm{a} \mathrm{standard} \mathrm{pool} \mathrm{of} \mathrm{human}$ hyperparathyroid plasma. The lower limit of detectability of the
Table 3. Distribution of 38 infants with hypocalcemia (plasma calcium $\leq 7.5 \mathrm{mg} /$ dl) according to type of delivery, gestational age, and perinatal disorders

\begin{tabular}{|c|c|c|c|c|}
\hline Infant groups & $\begin{array}{l}\text { Total no. } \\
\text { of infants }\end{array}$ & $\begin{array}{l}\text { No. of in- } \\
\text { fants with } \\
\text { hypocalce- } \\
\text { mia }\end{array}$ & $\begin{array}{l}\text { \% of in- } \\
\text { fants with } \\
\text { hypocalce- } \\
\text { mia }\end{array}$ & $\begin{array}{l}\text { \% of total } \\
\text { hypocal- } \\
\text { cemic in- } \\
\text { fants by in- } \\
\text { fant groups }\end{array}$ \\
\hline Vaginal deliveries & 130 & 21 & 16 & 55 \\
\hline Cesarean sections & 60 & 17 & 28 & 45 \\
\hline $\begin{array}{l}\text { Healthy }{ }^{1} \text { term in- } \\
\text { fants }\end{array}$ & 106 & 4 & 4 & 11 \\
\hline $\begin{array}{l}\text { Healthy preterm }{ }^{2} \\
\text { infants }\end{array}$ & 28 & 6 & $(21)^{3}$ & 16 \\
\hline IDM, total no. & 22 & 11 & $(50)$ & 29 \\
\hline Preterm IDM & 10 & 6 & $(60)$ & 16 \\
\hline Asphyxia, total no. & 25 & 15 & $(60)$ & 39 \\
\hline $\begin{array}{l}\text { Preterm with as- } \\
\text { phyxia }\end{array}$ & 15 & 8 & $(60)$ & 21 \\
\hline
\end{tabular}

${ }^{1}$ Healthy, nonasphyxiated, non-IDM.

${ }^{2}$ Two hypocalcemic infants were in the postterm age group $(n=9)$.

${ }^{3}$ Percent figures for small patient numbers are listed in parentheses.

assay was $21 \mu \mathrm{l} \mathrm{Eq} / \mathrm{ml}$. The assay permits the detection of circulating hormone levels in $>95 \%$ of normal children and adults. PTH concentrations determined in 118 healthy adult subjects were $76 \pm 29 \mu \mathrm{l} \mathrm{Eq} / \mathrm{ml}$ (mean $\pm 2 \mathrm{SD})$. The within-assay coefficient of variation calculated from 38 single determinations was $10 \%$. The across-assay coefficient of variation determined in 20 consecutive assays was $11.7 \%$.

\section{STATISTICAL ANALYSIS}

Computer analysis of data was performed using the statistical package written by the Western Michigan University (22). Nonparametric tests were selected for statistical evaluation since the available data did not show sufficiently normal distribution for analysis by Student's $t$ test. The two-tailed Mann-Whitney $U$ test was chosen for data analysis, since it has a power efficiency of about $95 \%$ of the $t$ test, even for moderate size samples, without the restrictive assumptions and requirements associated with Student's $t$ test $(3,29,31)$. Both individual and sequential values of PTH and calcium concentrations were included for statistical analysis if different patient groups were compared day by day (Figs. 1 and 2), ensuring that no patient had a chance to contribute 


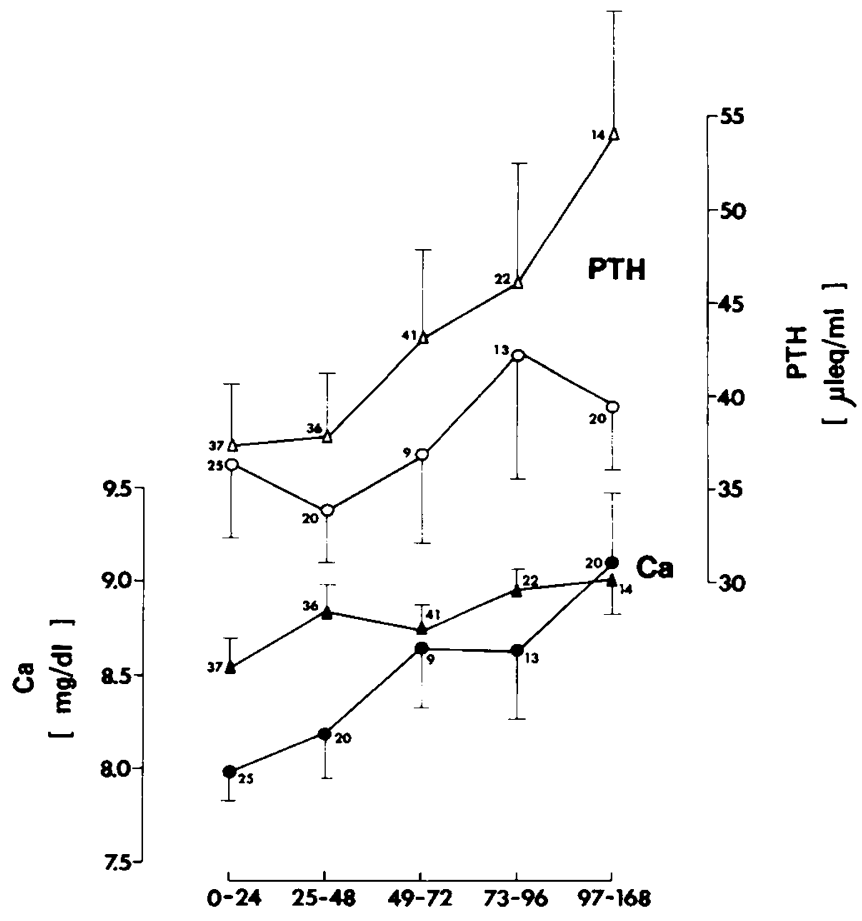

POSTNATAL AGE IN HOURS

Fig. 1. PTH and calcium concentrations (mean $\pm \mathrm{SE}$ ) in plasma specimens collected from premature $(O, \Theta)$ as compared with full term $(\triangle$, ๑) infants. Figures next to the symbols indicate the number of patient samples analyzed.

more than once to any given set of data. When data from different postnatal ages were compared longitudinally within or between patient groups, only one value of any set of sequential data was chosen for each patient by random number assignment. This guaranteed that only independent samples were included for statistical analysis. This latter group of values hereafter will be referred to as the "random" or "independent sample."

\section{RESULTS}

\section{GENERAL OBSERVATIONS}

Circulating PTH concentrations were detectable in 295 of 309 blood specimens (>95\%) collected from 190 newborns during the first week of life. Only 14 specimens $(4.5 \%)$ had undetectable PTH levels, i.e., hormone concentrations less than $21 \mu \mathrm{l} \mathrm{Eq} / \mathrm{ml}$. Of these, five samples were collected on day 1 , six on day 2 , and one sample each on days 3,4 , and 5 . According to gestational age groups, undetectable PTH levels were found in 5 of 87 samples (6\%) from premature infants, 7 of 212 samples (3\%) from term infants, and 2 of 10 postterm infants. Four of the 14 newborns with undetectable PTH levels were female but 10 were male. Furthermore, male $(n=26)$ newborns were more frequently affected by neonatal hypocalcemia than females $\left(n=12 ; \chi^{2}=\right.$ 5.72; $P<0.025)$.

Mean $( \pm$ SE) PTH concentrations in cord blood $(28.5 \pm 2.5 \mu \mathrm{l}$ Eq; $n=10$ ) were lower than those in postnatal blood specimens (Figs. 1 and 2). However, two cord blood samples from asphyxiated newborns showed elevated PTH levels of 86 and $63 \mu 1$ $\mathrm{Eq} / \mathrm{ml}$. The mean calcium concentration in cord blood was 10.62 $\mathrm{mg} / \mathrm{dl}$ (range $9.8-11.2 \mathrm{mg} / \mathrm{dl}$ ). Fifteen samples from nine newborns (three preterm, five term, and one postterm) showed PTH levels in the range of $100-182 \mu \mathrm{lEq} / \mathrm{ml}$. These levels showed no correlation with sex, gestational or postnatal age, birth weight, type of delivery, or APGAR score. Corresponding plasma calcium concentrations in these samples ranged from $7.6-9.8 \mathrm{mg} / \mathrm{dl}$ (mean $8.8 \mathrm{mg} / \mathrm{dl}$ ). Serial PTH determinations between days 1 and 6 carried out in three of these patients showed little fluctuation in concentrations as illustrated by the following figures: term AGA infant 57 had plasma PTH levels of 171, 135, 134, 137, and 130 $\mu \mathrm{Eq} / \mathrm{ml}$ determined on days $2,3,4,5$, and 6 while in term large for gestational age infant 14, PTH concentrations of 100, 105, 74, and $98 \mu \mathrm{l} \mathrm{Eq} / \mathrm{ml}$ were measured on days 1, 2, 3, and 4. Similar observations have been reported in the literature; the etiology and biologic significance of perinatal PTH concentrations in the hyperparathyroid range remains to be elucidated.

\section{TERM AGA INFANTS}

Values for plasma PTH and calcium concentrations were determined in 150 samples from 97 term AGA newborns and compared with those obtained in preterm infants and IDM (Fig. 1 and 2). Mean PTH levels in term AGA subjects tended to be higher than those observed in the other two groups of patients throughout the 7-day period of observation, but the differences were not significant. However, mean serum calcium concentraticns on days 1 and 2 were significantly higher in term AGA in comparison to premature infants $(P<0.005$ and $<0.03$, respectively), and on day 4 in term AGA infants when compared with IDM $(P<0.01)$. There was little change of PTH concentrations over the first $48 \mathrm{hr}$ in term infants. Between days 2 and 3, however, there was a marked increase in PTH concentrations; mean PTH levels for days 3 and 4 combined were significantly higher than the mean of days 1 and 2 combined $(P<0.02)$. Plasma calcium concentrations increased between days 1 and 2, before a rise in plasma PTH was detectable, and there was a slow but continuous increase in plasma calcium levels thereafter.

\section{IDM AND PREMATURE INFANTS}

Mean PTH levels did not show a significant change in IDM or premature infants until the age of $72 \mathrm{hr}$ (Fig. 1 and 2). Between days 3 and 4 an increase in PTH levels was observed in both groups of patients. Statistical analysis of the random sample of IDM and premature infants showed that mean PTH concentrations on days 1-3 were significantly lower than those on days 4-7
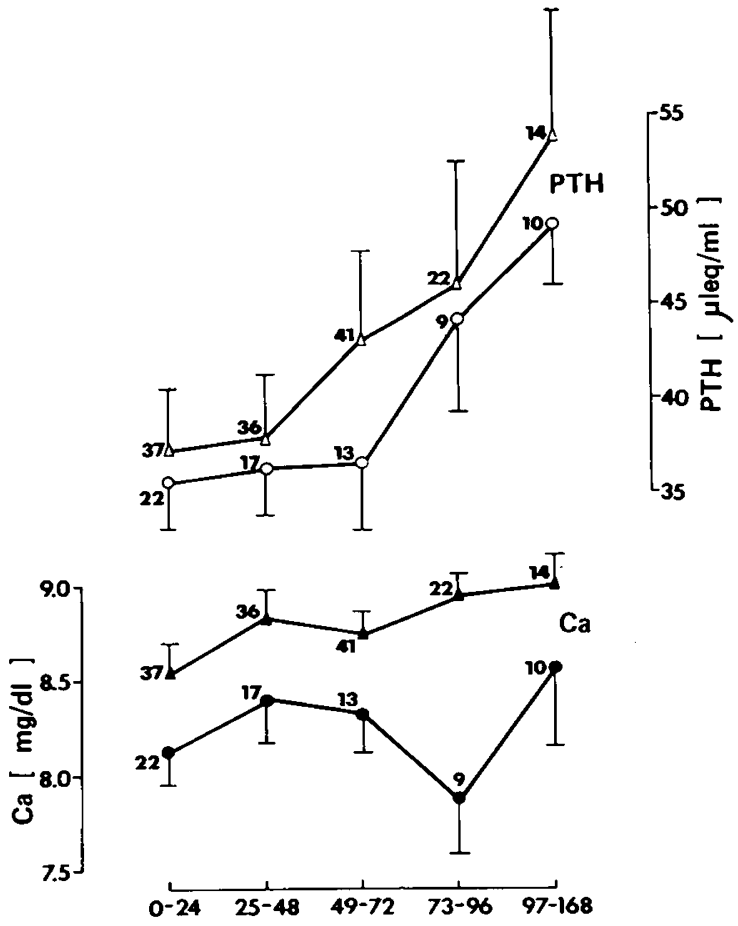

POSTNATAL AGE IN HOURS

Fig. 2. PTH and calcium concentrations (mean $\pm \mathrm{SE}$ ) in infants of diabetic mothers $(O, \ominus)$ as compared with full term $(\Delta, \boldsymbol{\Delta})$ infants. Figures next to the symbols indicate the number of patient samples analyzed. 
$(P<0.02)$. Early plasma calcium concentrations were low in the premature infants and increased rapidly until day 3 , again before any noticeable PTH increase could be detected. By the end of the first week of life, calcium levels were in the normal range of term AGA infants. Plasma calcium levels on day 1 were less depressed in the IDM than those in premature infants, but showed little tendency to rise thereafter. On day 4 , there was a marked drop of plasma calcium concentrations in IDM; this drop was not observed in any other group of infants. By the end of the first week of life, plasma calcium concentrations in the IDM group were still considerably lower than those in term AGA infants.

\section{INFANTS WITH ASPHYXIA}

Twenty-five newborns presented with perinatal asphyxia as defined by a 5-min APGAR score less than seven. Of these, 14 were premature. The total number of patients $(n=25)$ and individual blood specimens $(n=39)$ were too small to permit statistical analysis by days (Fig. 3). However, the mean PTH concentration during the first two days of life $(53.8 \mu \mathrm{l} \mathrm{Eq} / \mathrm{ml})$ was higher than that in age-matched nonasphyxiated term infants $(P$ $<0.01)$, while the mean plasma calcium level $(7.82 \mathrm{mg} / \mathrm{dl})$ was significantly lower $(P<0.01)$. In addition, PTH concentrations, averaged over the first week, were significantly higher in the asphyxiated infants as compared with those of nonasphyxiated newborns in the random sample $(P<0.007)$. In spite of these high PTH concentrations, hypocalcemia was common among the asphyxiated infants. Fifteen of 25 patients $(60 \%)$ presented with serum calcium levels of $\leq 7.5 \mathrm{mg} / \mathrm{dl}$ on one or more occasions during the neonatal period. Four infants with calcium concentration $\leq 7.5 \mathrm{mg} / \mathrm{dl}$ received iv calcium between the first and second days of life. Two more infants received calcium medication between 3 and 4 days. The temporary increase in mean plasma calcium concentration between 1 and 2 was probably related to exogenous calcium administration. Mean plasma PTH concentrations did not change noticeably in response to rising calcium levels. Small patient numbers precluded separate statistical anal-

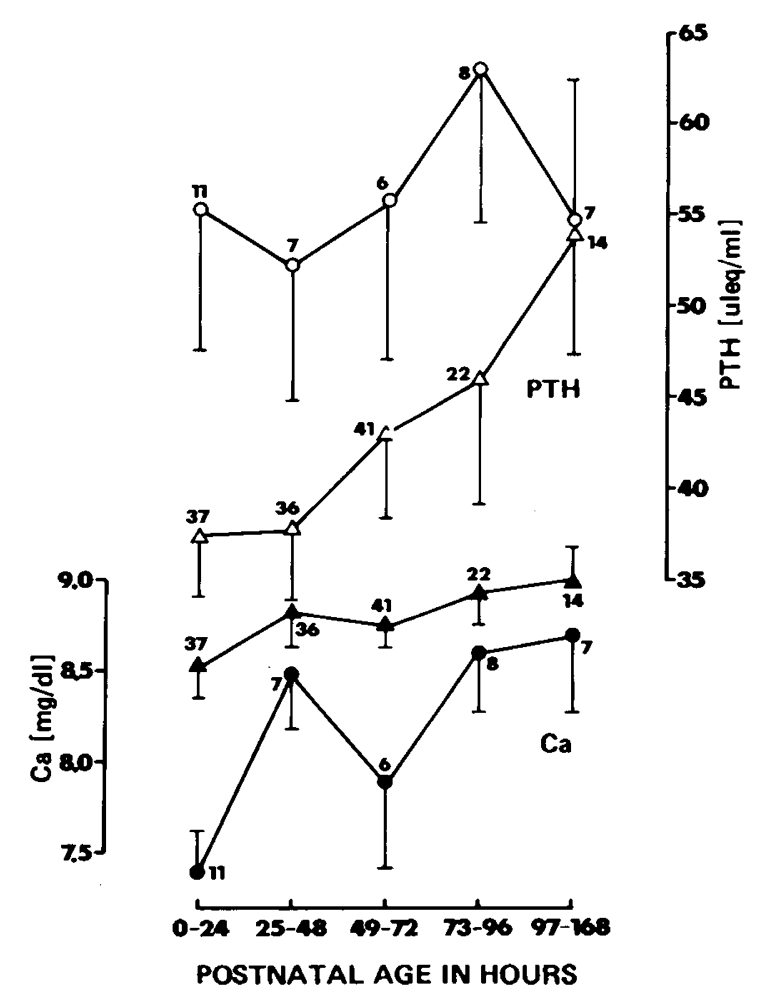

Fig. 3. PTH and calcium concentrations (mean $\pm \mathrm{SE}$ ) in asphyxiated infants $(O, \bullet)$ as compared with full term $(\triangle, \Delta)$ infants. Figures next to the symbols indicate the number of patient samples analyzed. ysis of treated and untreated infants. Combined analysis of both groups, however, appeared to be justified since increasing calcium concentrations in treated patients would not be expected to induce a rise in plasma PTH.

\section{INFANTS WITH HYPOCALCEMIA}

Thirty-eight newborns presented with clinical symptoms and/or laboratory evidence of hypocalcemia. Two-thirds of these infants $(n=26)$ were male. The mean (and SE) plasma calcium concentration in these infants was $6.78 \pm 0.1 \mathrm{mg} / \mathrm{dl}$. Table 3 lists the number of hypocalcemic subjects for different infant groups and corresponding percent figures. The highest incidence of hypocalcemia was encountered in IDM and asphyxiated infants. Respectively, 50 and $60 \%$ of these patients demonstrated plasma calcium concentrations of $\leq 7.5 \mathrm{mg} / \mathrm{dl}$ during the first week of life, and this incidence was essentially similar in premature and term IDM/asphyxiated infants (Table 3). Excluding IDM and asphyxiated newborns, however, prematurity seemed to be more frequently associated with hypocalcemia than term gestational age ( 6 of 28 versus 4 of $106 ; \chi^{2}=7.6, P<0.01$ ). It appears that prematurity, asphyxia, and being born to a diabetic mother, all may serve as predisposing factors for perinatal hypocalcemia; however, the latter two factors may override the effect of prematurity.

\section{DISCUSSION}

Perinatal calcium homeostasis is regulated by a number of endocrine $(13,21,38,46)$ and nonendocrine $(4,10,27,28,44)$ factors. Although PTH would be expected to play a key role among the endocrine factors involved, this has been difficult to document. Direct radioimmunoassay measurements of circulating PTH concentrations in newborns have shown conflicting results. The present study corroborates some of the observations of David and Anast (13) but differs in others. Our data are in agreement that PTH concentrations are depressed in term AGA infants during the first 2 days of life, and increase significantly thereafter (Fig. 1). Also, the PTH rise in IDM and premature infants is delayed until the age of 4 days (Figs. 1 and 2). At variance with the findings of David and Anast (13), who reported undetectabie serum PTH concentrations in over $80 \%$ of cord blood specimens and in $66 \%$ of blood samples from term infants below the age of $48 \mathrm{hr}$, circulating PTH levels in the present study were measurable in over $95 \%$ of blood specimens. In addition, PTH was detectable in 12 of 12 cord blood samples despite elevated calcium concentrations.

Several lines of evidence from in vitro (45) and in vivo experiments (8) have suggested the possibility that small amounts of PTH may be secreted, despite the presence of supraphysiologic calcium concentrations. More recently, Mayer et al. (30), by means of in vivo catheter studies in calves, demonstrated that low level basal PTH secretion did persist over an observation period of up to $35 \mathrm{hr}$ despite marked hypercalcemia induced by a continuous calcium infusion. Hypercalcemia of much longer duration occurs physiologically in the human fetus over the final weeks of gestation, during which time an active placental transport mechanism keeps circulating calcium concentrations in the fetus about 2 $\mathrm{mg} / \mathrm{dl}$ above corresponding maternal plasma levels $(35,36)$. Mean calcium concentrations in human cord blood have varied from $9.2-11.0 \mathrm{mg} / \mathrm{dl}$ in several reports $(2,14,36)$. The mean value of $10.6 \mathrm{mg} / \mathrm{dl}$ in this study is above the $2 \mathrm{SD}$ range of serum calcium established in our laboratory for normal adults $(9.4 \pm 0.85 \mathrm{mg} / \mathrm{dl}$, $n=118$ ). The demonstration of measurable PTH activity persisting in cord blood despite hypercalcemia suggests that PTH is not entirely suppressed in the human fetus and newborn (40).

Nonetheless, stimulated PTH release in response to postnatally decreasing calcium concentrations appeared to be delayed and blunted in neonates, except in asphyxiated newborns. Thus, mean PTH concentrations in both term and preterm infants remained depressed throughout the first days of life, despite low plasma 
calcium levels (Figs. 1 and 2). In asphyxiated newborns, however, mean PTH concentrations were significantly $(P<0.007)$ increased above levels observed in term infants (Fig. 3), and this increase appeared to occur regardless of plasma calcium concentrations. From these observations it follows that factors other than serum calcium may be involved in the regulation of perinatal PTH secretion. These factors appear to be stress related, are effective in term as well as preterm infants, and seem to be operative at birth, i.e., $48-72 \mathrm{hr}$ before the parathyroid glands become responsive to changes in plasma calcium. Furthermore, at least in newborns, these factors may be able to override the suppressive effect of hypercalcemia on PTH secretion.

No direct evidence can be derived from our data as to the exact nature of these calcium-independent factors influencing newborn PTH secretion. Fischer et al. (18) have recently demonstrated that PTH release can be induced in cows by the infusion of epinephrine, and that this effect is mediated through a $\beta$ adrenergic receptor mechanism. Similar results have been obtained in human subjects (24). Also, it is well established that the parathyroid glands are encanvassed by a dense network of sympathetic nerve fibers $(1,51)$. In light of these anatomical and pharmacologic findings, our observations suggest the possibility that tonic basal, as well as stress-related PTH secretion in newborns, is under the influence of autonomic nervous system control. More specifically, adrenergic control of parathyroid gland secretion may be operative during the perinatal period before the PTH glands become responsive to hypocalcemia.

Hypocalcemia (plasma calcium $\leq 7.5 \mathrm{mg} / \mathrm{dl}$ ) was a frequent finding in IDM and asphyxiated infants (Table 2), and these two patient groups accounted for about two-thirds of all hypocalcemic newborns. In contrast to David and Anast (13), who reported depressed PTH levels in hypocalcemic neonates over the first 3-4 days of life, we found no difference between mean PTH levels in hypocalcemic and normocalcemic infants (39). A comparison of patients in the two studies indicates that there was a greater proportion of asphyxiated newborns among our hypocalcemic infants. The elevated PTH levels in these patients probably account for the higher mean hormone concentration in our study.

The etiology hypocalcemia in asphyxiated infants, despite the presence of elevated plasma PTH concentrations, remains unclear. There is evidence in human newborns that a transient pseudohypoparathyroidism-like state is present at birth and over the first several days of life $(9,26,27)$, probably reflecting an immaturity of the receptor-adenyl cyclase system in renal tubular as well as bone cells. Prostaglandin E compounds, which are capable of inhibiting PTH induced adenyl cyclase activity (6), may contribute to hypocalcemia by reducing renal phosphate clearance and enhancing neonatal hyperphosphatemia. Hypersecretion of cortisol in asphyxiated patients may antagonize the effect of 1,25-dihydroxycholecalciferol on intestinal calcium absorption. It may also inhibit vitamin D-mediated effects of PTH on calcium mobilization from bone. Furthermore, abnormal PTH compounds may be secreted during the period of perinatal adaptation and stress; these could accumulate in the circulation without exerting biologic effects. The extraordinarily elevated plasma PTH concentrations of $100 \mu \mathrm{l} \mathrm{Eq} / \mathrm{ml}$ observed in a few infants would be compatible with such an hypothesis.

Finally, the possibility of excessive calcitonin secretion antagonizing and actually overriding the effects of low circulating PTH during the perinatal life period has to be considered. There is evidence that the clear cell apparatus of the thyroid gland may be hyperplastic at birth as a result of sustained intrauterine hypercalcemia (23). Circulating calcitonin concentrations in cord blood have been reported variably as equal to (15), or elevated above corresponding maternal hormone levels (38). Unpublished data from our own studies (41) also show mean (and SE) calcitonin concentrations in cord blood $(80.5 \pm 2.8 \mathrm{pg} / \mathrm{ml})$ to be significantly higher than those hormone concentrations in the maternal circulation $(36.3 \pm 2.8 \mathrm{pg} / \mathrm{ml}, n=22 ; P<0.001)$. Moreover, as reported recently (40), an additional 5 - to 10 -fold increase of calcitonin concentrations above cord blood levels was consistently observed in newborn infants during the first $24-48 \mathrm{hr}$ of life, mean plasma calcitonin concentrations being highest in premature, asphyxiated, and hypocalcemic infants.

\section{CONCLUSION}

Circulating PTH was detectable in cord blood and in more than 95\% of neonatal blood specimens. However, an inverse relationship between plasma PTH and calcium concentrations was not demonstrable during the perinatal life period. Decreasing plasma calcium concentrations postpartum were not associated with a rise in plasma PTH, nor was intrauterine hypercalcemia associated with a complete suppression of PTH in cord blood. We suggest that nonsuppressible, basal PTH secretion may reflect autonomous parathyroid gland function.

Mean PTH levels in asphyxiated infants were higher than those in healthy newborns. Exogenous calcium administration in these infants, in spite of producing a significant increase in plasma calcium, had no demonstrable effect on plasma PTH concentrations. It thus appears that perinatal PTH secretion is poorly responsive to changes in plasma calcium but may be stimulated under stressful conditions such as asphyxia. There is indirect evidence to suggest that the autonomic nervous system may be involved in this stimulation.

The importance of PTH as a regulator of perinatal calcium metabolism remains uncertain. Hypocalcemia was common in asphyxiated newborns with relatively high plasma PTH levels, but was rarely observed in healthy term infants with comparatively low PTH concentrations. In addition, calcium levels in term infants were shown to rise prior to measurable increases in plasma PTH. Additional studies are needed to define the role and interactions of the autonomic nervous system versus endocrine-metabolic and nutritional factors in the regulation of perinatal calcium hemostasis.

\section{REFERENCES AND NOTES}

1. Altenhar, E.: Electron microscopical evidence for innervation of chief cells in human parathyroid gland. Experientia, 27: 1077, (1971).

2. Armstrong, W. D., Singer, L., and Makowski, E. L.: Placental transfer of fluoride and calcium. Am. J. Obstet. Gynecol., 107: 432 (1970).

3. Auble, D.: Extended tables for the Mann-Whitney Statistics. Bull. Inst. Educ. Res., Indiana Univ. 1, No. 2 (1953).

4. Barltrop, D., and Oppe, T. E.: Dietary factors in neonatal calcium homeostasis. Lancet, 2: 1333 (1970).

5. Battaglia, F. C., and Lubchenco, L. O.: A practical classification of newborn infants by weight and gestational age. J. Pediatr., 71: 159 (1967).

6. Beck, N. P., DeRubertis, F. R., Michelis, M. F., Fusco, R. D., Field, J. B., and Davis, B. B.: Effect of prostaglandin $E_{1}$ on certain renal actions of parathyroid hormone. J. Clin. Invest., 51: 2352 (1972).

7. Berson, S. A., Yalow, R. S., Aurbach, G. D., and Potts, J. T.: Immunoassay of bovine and human PTH. Proc. Natl. Acad. Sci. USA, 49: 613 (1963).

8. Blum, J. W., Mayer, G. P., and Potts, J. T.: Parathyroid hormone responses during spontaneous hypocalcemia and induced hypercalcemia in cows. Endocrinology, 95: 84 (1974).

9. Connelly, J. P., Crawford, J. D., and Watson, J.: Studies of neonatal hyperphosphatemia. Pediatrics, 30: 425 (1962).

10. Copp, D. H., and Kuczerpa, A. V.: A new bioassay for calcitonin and effect of age and dietary $\mathrm{Ca}$ on the response. In: $\mathrm{S}$. Taylor: Calcitonin: Proceedings of the symposium on thyrocalcitonin and the C-cells, p. 18 (London, 1968).

11. Craig, W. S., and Buchanan, M. F. G.: Hypocalcemic tetany developing within 36 hours of birth. Arch. Dis. Child., 33: 505 (1958).

12. David, L., and Anast, C. S.: Evaluation of parathyroid function in newborns. In: B. Frame, A. M. Parfitt, ad H. Duncan: Clinical Aspects od Metabolic Bone Disease, p. 661, International Congress Series no. 270 (Excerpta Medica Foundation, Amsterdam, 1973).

13. David, L., and Anast, C. S.: Calcium metabolism in newborn infants. J. Clin Invest., 54: 287 (1974).

14. Delivoria-Papadopoulis, M., Battaglia, F. C., Bruns, P.D., and Meschia, G.: Total protein-bound and ultrafiltrable calcium in maternal and fetal plasmas. Am. J. Physiol., 213: 363 (1967).

15. Dirksen, H. C., and Anast, C. S.: Hypercalcitonemia and neonatal hypocalcemia. Pediatr. Res., 11: 424, (1977)

16. Dubowitz, L. M., Dubowtiz, V., and Goldberg, C.: Clinical assessment of gestational age in the newborn infant. J. Pediatr., 77: 1 (1970).

17. Fanconi, G., and Prader, A.: Transient congenital idiopathic hypoparathyroidism. Helv. Paediatr. Acta, 22: 342 (1967).

18. Fischer, J. A., Blum, J. W., and Binswanger, U.: Acute parathyroid hormone response to epinephrine in vivo. J. Clin. Invest., 52: 2434 (1973). 
19. Gardner, L. J., MacLahlan, E. A., Pick, W., Terry, M. L., and Butler, A. M.: Etiologic factors in tetany of newly born infants. Pediatrics, 5: 228 (1950).

20. Gittleman, I. F., Pincus, J. B., Schmertzler, E., and Saito. M.: Hypocalcemia occurring on the first day of life in mature and premature infants. Pediatrics, 18: 721 (1956).

21. Hillman, L., and Haddad, J.: Perinatal vitamin D metabolism II: Serial 25 hydroxyvitamin $D$ cocentrations in sera of term and premature infants. $J$. Pediar., 86: 928 (1975).

22. Houchard, R.: STATPACK, Statistical Package of DECSYSTEM-10. Western Michigan University, Kalamazoo, Michigan

23. Kalina, M., Foster, C. G., Clark, M. B., and Pearse, A. G. E.: C-cells in man. In: S. Taylor and G. Foster: Calcitonin, 1969 Proceedings of the 2nd International Symposium, p. 262 (Heinemann Medical Books, Ltd., London, 1970).

24. Kukreja, S. C., Hargis, G. K., Bowser, E. N., Henderson, W. J., Fisherman, E. W., and Williams, G. A.: Role of adrenergic stimuli in parathyroid hormone secretion in man. J. Clin.Endocrinol. Metab., 40: 478 (1975).

25. Lequin, R. M., Hackeng, W. H. L., and Schopman, W.: A radioimmunoassay for parathyroid hormone in man. II. Measurement of PTH in human plasma by means of a RIA for bovine hormone. Acta Endocrinol., 63: 655 (1970).

26. Linarelli, L. G., Bobik, C., and Bobik, J.: Renal cyclic AMP response to PTH in premature hypocalcemic infants. J. Pediatr., 84: 914 (1974).

27. Linarelli, L. G., Bobik, J., ad Bobik, C.: Newborn urinary cyclic AMP and developmental renal responsiveness to parathyroid hormone. Pediatrics, 50:14 (1972).

28. McCory, W. W., Forman, C. W., McNamara, H., and Barnett, H. L.: Renal excretion of inorganic phosphate in newborn infants. J. Clin. Invest., 31: 357 (1952).

29. Mann, H. B., and Whitney, D. R.: On a test of whether one of two variables is stochastically larger than the other. Ann. Math. Statist., 18: 50 (1947).

30. Mayer, G. P., Habener, J. F., and Potts, J. T.: Parathyroid hormone secretion in vivo. J. Clin. Invest., 57: 678 (1976).

31. Mood, A. M.: On the asymptotic efficiency of certain nonparametric two sample tests. Ann. Math. Statist., 25: 514 (1954).

32. Oh, W.: Unpublished data.

33. O'Sullivan, J. B., and Mahan, C. M.: Criteria for the oral glucose tolerance test in pregnancy. Diabetes, 13: 278 (1964).

34. Radde, I. C., Hoffken, B., Parkinson, D. K., Sheepers, J., and Luckham, A.: Practical aspects of a measurement technic for calcium ion activity in plasma. Clin. Chem., 17: 1002 (1971).

35. Radde, I. C., Shami, Y., and Parkinson, D. K.: The placental calcium pump. Pediatr. Res., 5: 417 (1971).

36. Reitz, R. E., Daane, T. A., Woods, J. D., and Weinstein, R. L.: Human parathyroid hormone (HPTH)-calcium interrelations in pregnancy and newborn infants. Fourth International Congress of Endocrinology, Washington, DC, International Congress Series no. 256, p. 208 (Excerpta Medica, Amsterdam, 1972).

37. Roberton, N. R. C., and Smith, M. A.: Early neonatal hypocalcemia. Arch. Dis.
Child., 50: 604 (1975).

38. Samaan, N. A., Anderson, G. D., and Adam-Mayne, M. E.: Immunoreactive calcitonin in the mother, neonate, child, and adult. Am. J. Obstet. Gynecol.. 121: 622 (1975).

39. Schedewie, H. K., Krutzik, S. R., Dodge, M., Fiser, W. P., and Odell, W. D.: First day hypocalcemia: role of PTH? Clin. Res., 25: 400A (1977).

40. Schedewie, H. K., Krutzik, S. R., Fiser, W. P., Dodge, M., and Odell, W. D.: Autonomous non-suppressible PTH secretion in the human newborn. Fed. Proc., 38: 296 (1977).

41. Schedewie, H. K., Odell, W. D., Fisher, D. A., Deftos, L. J., Cantor, T. L., and Dodge, M.: Calcitonin and perinatal calcium homeostasis. In preparation.

42. Segre, G. V., Niall, H. D., Habener, J. F., and Potts, J. T.: Metabolism of parathyroid hormone. Am. J. Med., 56: 774 (1974).

43. Segre, G. V., Treagear, G. W., and Potts, J. T.: Development and application of sequence-specific radioimmunoassays for analysis of the metabolism of parathyroid hormone. In: B. W. O'Malley and J. G. Hardman: Methods in Enzymology, Vol. 37, Part B, p. 38 (Academic Press, Inc., NY, 1975).

44. Stimmler, L., Snodgrass, G. J., Gupta, Y., Stothers, J. K., and Brown, D. Relation between changes in plasma calcium in the first week of life and renal function. Arch. Dis. Child, 50: 786 (1975).

45. Targovnik, J. H., Rodman, J. S., and Sherwood, L. M.: Regulation of parathyroid hormone secretion in vitro: Quantitative aspects of calcium and magnesium ion control. Endocrinology, 88: 1477 (1971).

46. Tsang, R. C., Light, I. J., Sutherland, J. M., and Kleinman, L. I.: Possible pathogenetic factors in neonatal hypocalcemia of prematurity. J. Pediatr., 82: 423 (1973).

47. Tsang, R. C., and Oh, W.: Neonatal hypocalcemia in low birth weight infants. Pediatrics, 45: 773 (1970).

48. Tsang, R. C., Wen Chen, I., Friedman, M. A., and Chen, I.: Neonatal parathyroid function: Role of gestational age and postnatal age. J. Pediatr., 83: 728 (1973).

49. Whatney, P. J. M., and Rudd, B. T.: Calcium metabolism in pregnancy and in the newborn. J. Obstet. Gynaecol. Br. Commonw., 81: 210 (1974).

50. White, P.: Symposium on diabetes mellitus: Pregnancy complicating diabetes. Am. J. Med., 7: 609 (1949)

51. Yeghiayan, E., Rojo-Ortega, J. M., and Genest, J.: Parathyroid vessel innervation: An ultrastructural study. J. Anat., 112: 137 (1972).

52. Informed consent was obtained using Parent Consent Form P-2012 approved by the Human Use Committee at Harbor General Hospital-UCLA.

53. We express our great appreciation to Dr. Albert Nichols and John Potts for their advice and support during this study. We also want to express our gratitude to Patti Walden and Mary Badenoch for their excellent secretarial assistance.

54. This research was supported by the German Research Foundation Grant Sche $119 / 4$.

55. Received for publication August 15, 1977

56. Accepted for publication February 15, 1978. 